\title{
Marina Sozzi, Virtuoso e felice. Il cittadino repubblicano di C.-A. Helvétius
}

\section{Gianmaria Zamagni}

\section{(2) OpenEdition}

1 Journals

\section{Edizione digitale}

URL: https://journals.openedition.org/studifrancesi/40803

DOI: 10.4000/studifrancesi.40803

ISSN: 2427-5856

\section{Editore}

Rosenberg \& Sellier

\section{Edizione cartacea}

Data di pubblicazione: 1 juillet 2004

Paginazione: 200-201

ISSN: 0039-2944

\section{Notizia bibliografica digitale}

Gianmaria Zamagni, «Marina Sozzi, Virtuoso e felice. I/ cittadino repubblicano di C.-A. Helvétius», Studi Francesi [Online], 142 (XLVIII | I) | 2004, online dal 30 novembre 2015, consultato il 09 septembre 2021. URL: http://journals.openedition.org/studifrancesi/40803 ; DOI: https://doi.org/10.4000/studifrancesi. 40803

Questo documento è stato generato automaticamente il 9 septembre 2021.

\section{(c)}

Studi Francesi è distribuita con Licenza Creative Commons Attribuzione - Non commerciale - Non opere derivate 4.0 Internazionale. 


\title{
Marina Sozzi, Virtuoso e felice. Il cittadino repubblicano di C.-A. Helvétius
}

\author{
Gianmaria Zamagni
}

\section{NOTIZIA}

MARINA SOZZI, Virtuoso e felice. Il cittadino repubblicano di C.-A. Helvétius, Pisa, ETS, 2002, pp. 200.

1 Il volume di Marina Sozzi è dedicato all'opera helveziana De l'Homme (1772, postuma, per evitare la censura). Essa, del precedente De l'Esprit, rappresenta un approfondimento interessato soprattutto alle tematiche dell'educazione e della politica. I cinque capitoli che danno corpo a Virtuoso e felice rispondono direttamente ai principali temi di quel trattato: la visione dell'uomo, un'originale teoria dell'educazione alla cultura, la riflessione sul lusso, quella sulla comunità politica ideale, e infine il discorso sulla felicità.

2 Nella propria Introduzione, Sozzi delinea le dipendenze di Helvétius verso il pessimismo rousseauiano dei due Discours e, nel contempo, verso la fiducia nel progresso e la lotta al pregiudizio di Voltaire e D'Holbach, mostrandolo, in questo dualismo, alla ricerca d'una difficile terza via, che combatta le disuguaglianze sociali pur nella consapevolezza della possibile ricaduta nel dispotismo o sotto il peso di più giovani società, repubblicane $\mathrm{e}$ guerriere. L'Homme presenta nondimeno alcuni rilevanti problemi di ordine filologico che vengono qui discussi: il trattato fu infatti ripristinato dei tagli, ma anche vittima di interpolazioni per opera del primo curatore delle CEuvres complètes, l'abbé Lefebvre de La Roche, che intese fare di Helvétius un precursore della Rivoluzione. In questa Introduzione, ancora, sono seguite le linee principali della storia della critica: non sono infatti mancate intepretazioni con riferimento ad ideologie di là da venire, quali quella di Helvétius anticipatore dei totalitarismi; tuttavia Sozzi giustamente ritiene «molto 
più produttivo [...] farlo dialogare coi suoi contemporanei» (p. 18), ed, in particolare, proprio con Rousseau, che nel corso del volume è contrappunto costante. Helvétius risulta allora assai prossimo al paradigma repubblicano (per come viene inteso da J. G. A. Pocock), per quanto alcuni aspetti possano risultare contraddittori in questo quadro. Anche dal punto di vista del materialismo, il De l'Homme viene considerato come specchio di una concezione piuttosto atipica, nella quale il determinismo è più d'ordine storico-sociale che fisico-naturale. In questo senso si comprende anche l'attenzione di Helvétius per 1'educazione.

3 Proprio secondo queste linee si muove il primo capitolo, «L'uomo»: i debiti del philosophe riguardo al materialismo sono rintracciati nella tradizione che unisce Locke a Condillac, piuttosto che nei medici materialisti e La Mettrie (quest'ultimo rappresenta un altro punto di riferimento costante nel volume). L'ignoranza della fisiologia coeva non è dunque casuale, «ma è strettamente funzionale al progetto di sottolineare 1'importanza dell'educazione, e, su scala più ampia, della legislazione, nella costruzione dell'uomo e della società» (p. 33). È attraverso quest'ultima che si creano le differenze sociali, non da altri limiti naturali: Helvétius si schiera infatti contro la presunta inferiorità dei neri e delle donne, poiché la mente umana è concepita come tabula rasa, materiale su cui l'educazione lavora fin dalla fase prenatale. Il sentimento che è addirittura innato invece nell'uomo, e invero «le seul de cette espèce» (p. 49) è l'interesse, connesso a quella teoria dell'amore per il potere, implicita in tutte le forme di governo, che portò Helvétius a diretto contrasto con i diversi principî dell'Esprit des Lois di Montesquieu (virtù, onore, crainte).

4 L'educazione dunque, di cui Sozzi tratta al capitolo secondo, non è tanto il prodotto di alcuni individui o istituzioni ad essa preposti, ma frutto di tutto l'ambiente in cui l'uomo, dalla culla alla tomba, si trova a vivere. È in questo senso che questa tematica è strettamente connessa alla politica: per quanto le lunghe catene di cause e concause fanno talora terminare nel caso l'influenza esercitata sull'individuo, l'educazione, lungi da essere come nell'Emile di Rousseau frutto del rapporto tra un maestro e un discepolo, è data da «un vasto progetto educativo» (p. 72), che è sociale e politico, nella forma non della repressione delle passioni, ma della valorizzazione di quegli interessi privati che coincidono con l'interesse comune.

5 La critica al lusso, di cui si occupa il capitolo terzo, viene smorzandosi tra la prima posizione helveziana, espressa nel De l'Esprit, ove si trova una netta condanna, e la trattazione del De l'Homme, poiché in quest'ultimo il philosophe, dopo essersi confrontato con il dibattito accesissimo dell'epoca, giunge a considerare un genere positivo di lusso accanto a uno negativo, stabilendo la discriminante tra $\mathrm{i}$ due in una questione di giustizia distributiva: «il male che sta alla base delle distorsioni della vita sociale, è dunque la diseguaglianza economica, le cui conseguenze sono della massima gravità» (p. 107). Il tema stesso del dispotismo è connesso a questo della diseguaglianza: il dispotismo è infatti il coniugarsi della ricchezza con il potere.

6 E proprio questa definizione di dispotismo può essere convenientemente intesa come filo conduttore della parte successiva, «La comunità ideale». Il modello repubblicano di Helvétius deve molto alla lettura di Rousseau: come nell'opera di quest'ultimo, esso è basato sulla diretta partecipazione dei cittadini alla cosa pubblica, poiché la sola libertà è l'obbedienza aile leggi che la volontà generale ha dato a ciascuno: «nessuno deve essere superiore alla legge, né individui (neppure se sovrani) né tanto meno gruppi di interesse, o corporazioni interne allo Stato (religiose o politiche)» (p. 132). La piccola 
estensione del territorio è dunque necessaria, fatto salvo il caso della confederazione, che è l'unica possibilità per mantenere i valori repubblicani di una più grande nazione. Rispetto a questo modello, il dispotismo rappresenta il pericolo sempre in agguato, «il luogo oscuro dove può venire nullificato ogni tentativo di riforma [...] l'inferno laico della politica» (p. 170) in cui dominano i ricchi divenuti potenti, assieme alle proprie corporazioni e consorterie, ver l'uso privato delle leggi, a detrimento del bene comune.

7 L'ultimo capitolo, infine, tratta della concezione helveziana della felicità. Questa è data dall'attività e dall'operosità: sono l'ozio, da una parte, e lo sfruttamento del lavoro, dall'altra, a costituire l'antitesi alla felicità. Questa si fonda materialisticamente, per Helvétius, nella soddisfazione dei desideri, ma necessita di una strategia consistente nel «limitare i propri desideri in modo che essi siano realizzabili» (p. 183).

Il volume di Marina Sozzi presenta dunque un ampio quadro delle ultime concezioni helveziane, quelle presenti nel De l'Homme, talora contrapponendole, talora avvicinandole a Rousseau, riuscendo tuttavia ad inquadrare il philosophe all'interno della grande tradizione repubblicana, pur al di là di alcune aporie del pensatore, che del resto risultano comprensibili data l'ampiezza della sua ricerca filosofica. 